Dhaka Univ. J. Biol. Sci. 28(1): 111-119, 2019 (January)

\title{
EVALUATION OF THE STATUS OF THREATENED CATFISH BAGARIUS BAGARIUS (HAMILTON, 1822) FROM THE PADMA AND MEGHNA RIVER STRETCHES OF BANGLADESH
}

\author{
Bijoya Paul, Md. Foijul Hasan ${ }^{1}$, Md. Monirul Islam*, Goutam Kumar Kundu², \\ Gouri Mondal, Samapti Saha and Md. Ghulam Mustafa \\ Department of Fisheries, University of Dhaka, Dhaka-1000, Bangladesh \\ Key words: Bagarius bagarius, Biodiversity, Conservation
}

\begin{abstract}
Bagarius bagarius (Hamilton, 1822), a freshwater catfish species, is important as food and game fish in Bangladesh, Bhutan, India and Nepal. In Bangladesh, it is known as Baghair and has been enlisted as critically endangered (CR) species in the IUCN Red List of Bangladesh 2000 and 2015, under the criteria A2cd version 3.1 mentioning declining trend in its population around $80 \%$ during the last 25 years ( 3 generation time). We studied the abundance of B. bagarius at 8 sites in three riverine habitats. We identified 8 individuals of $B$. bagarius from the Meghna river only (Shibpur site, Bhola Sadar). However, focus group discussion with fishers revealed that the species was frequently present in the catch from the river, although the abundance reduced considerably over the decade. We also found several other studies which reported the abundance of B. bagarius in different natural habitats. The findings from this study in combination with other published literature in the last 5 years indicated that the current status of $B$. bagarius in natural waters in Bangladesh do not fall below the threshold limits of CR species. Therefore, B. bagarius should be reclassified into a lower threatened status (but not Least Concern) than the current CR.
\end{abstract}

\section{Introduction}

Though freshwater comprises less than $0.3 \%$ of available global water, it contains remarkably more than 15,000 freshwater fish species out of 32,500(1). Developing countries hold about $94 \%$ of all freshwater fisheries from where millions of the world's poorest people get their food, nutrition and livelihoods for surviving ${ }^{(2)}$. Freshwater fishes have been significant in balancing between ecosystems, regulating food web dynamics and nutrient balances. Freshwater fishes comprised of almost 260 species in Bangladesh(3).

Regrettably, freshwater fishes are the most threatened group of vertebrates, based on more than 5,000 species assessed, to date, by the IUCN(4). In Bangladesh, the abundance of freshwater fishes have been declining from the 1970s because of habitat loss, massive

*Author for correspondence: <monirulislam153@yahoo.com>. ${ }^{2}$ World Fish Bangladesh and South Asia Office. ${ }^{3}$ Gwangju Institute of Science and Technology, Gwangju, South Korea. 
siltation, infrastructure development, drying up of water bodies, dewatering, conversion of wetlands, overfishing and aquatic pollution(5). Consequently, the share of inland capture fisheries has declined remarkably. In 1983-84, the contribution of inland capture fisheries to total fish production was $62.6 \%$, but in $2016-17$ it declined to $27.03 \%{ }^{(3)}$. Meanwhile, several fish species are on the verge of extinction, while many others are facing the risk of extinction in future(5).

For assessing the risk of species extinction, the International Union for Conservation of Nature (IUCN) is recognized global authority for classifying species into different threat categories varying from high to low expectation of extinction(5). Following a systematic evaluation, IUCN lists the species under seven different categories in the IUCN Red List of Threatened Species. Among the seven categories, two are for species those are already extinct (Extinct and Extinct in the wild), three are for those considered as threatened (Critically Endangered, Endangered, and Vulnerable), two are for those are not yet threatened (Near Threatened and Least Concern), whereas species without enough information to perform an evaluation are categorized as Data Deficient (6).Thus, the IUCN Red List of Threatened Species enables conservation planners and decision makers to prioritize species when allocating resources for their conservation.

IUCN first assessed the conservation status of species from Bangladesh in 2000 and 54 fish species had been reported as threatened out of 266 species $^{(6)}$. Fifteen years later, the second updated Red List of Threatened Species has been published in 2015 where 64 fish species were considered as threatened out of 253 freshwater fish species ${ }^{(5)}$. Thus more species have become threatened in 2015 compare to 2000. However, there is a decrease in Critically Endangered species by $25 \%$ and increase in Endangered and Vulnerable species by 21.4 and $78.5 \%$, respectively, in the 2015 assessment ${ }^{(5)}$.

Bagarius bagarius (Hamilton, 1822), a freshwater fish in Bangladesh, is important both as food and game fish ${ }^{(7)}$. It is carnivorous fish; feeds on small fishes, prawns, frogs, insects, etc. ${ }^{(8-9)}$. Therefore, B. bagarius is also important as a predator in top down control of riverine food web. It has been enlisted as Critically Endangered (CR) species in both IUCN Red lists for Bangladesh in 2000 and 2015(5-6). Species listed as CR in the red list categories are facing a very high risk of extinction in the wild. Therefore, CR designated species requires immediate conservation measures from government officials, researchers, conservationists, nature lovers and partner organizations. However, a number of studies have reported the occurrence and/or abundance of B. bagarius in riverine catches from various areas in Bangladesh(10-14). The regular availability of this species in wild habitats in contrast to its conservation status in IUCN red list demands a comprehensive and comparative study on abundance of B. bagarius in natural habitats. However, high variability in the methodology of these studies limits the comparative analysis of abundance of this species over various water bodies. IUCN assesses the threats level to a species based on the information from published books, research 
articles, scientific reports and other research findings, but information from the grey literature (unpublished material) and scientists' years of experience and observations are also used(5). Therefore, we collected primary data on abundance and reviewed the existing literature on B. bagarius to investigate its current status in Bangladesh.

\section{Materials and Methods}

The study was conducted in the three major rivers in Bangladesh - the Padma, the Meghna and the Tentulia. Fish specimen were collected from eight landing centers (Table 1) from previously contacted fishers. Gear specific fish specimen were collected during pre-monsoon (June), monsoon (August) and post-monsoon (October and February) seasons in 2016. Local fishers were solicited not to throw the non-target species by explaining the implication of both target and non-target species for this study. $10 \%$ of the total catch from each type of gear were collected as sample and immediately stored in an insulated box with sufficient ice for investigation in the laboratory. Individuals of $B$. bagarius were identified from the samples based on morphometric and meristic characteristics ${ }^{(9,15)}$. The number of individuals of B. bagarius in each sample were recorded and length $(\mathrm{cm})$ and weight $(\mathrm{g})$ of each individual were also recorded to the first decimal place.

Table 1. Location of fish sampling sites in the three rivers in Bangladesh.

\begin{tabular}{llllll}
\hline River & Site No. & Landing station & Union & Upazila & District \\
\hline Tentulia & S1 & Hajir Hat & Dashmina & Dashmina & Patuakhali \\
river & S2 & Bogi & Kalaya & Bauphal & Patuakhali \\
Meghna & S3 & Gosher Hat & Nilkamal & Char Fassion & Bhola \\
river & S4 & Shibpur & Shibpur & Bhola Sadar & Bhola \\
& S5 & Bohria Ghat & Sakhuya & Chandpur Sadar & Chandpur \\
& S6 & Meghna Ghat & Boidder Bazar & Sonargaon & Narayanganj \\
\multirow{2}{*}{$\begin{array}{l}\text { Padma } \\
\text { river }\end{array}$} & S7 & Chairman Station & Uttor Tarabonia & Bhedarganj & Shariatpur \\
\hline
\end{tabular}

Information on habitat, food habit, trophic status, threats of reduction, etc. of $B$. bagarius were collected from literature. Focus Group Discussions (FGD) were conducted along the river side at Shibpur, Bhola district during November 2016 to collect fishers' experience on habitats, catch trend, causes of decline/increase in abundance, etc. 15 local fishers were participated in an FGD that lasted for 3 hours.

The abundance data in the present study was combined with FGD findings and published articles and reports to assess the status of B. bagarius following the assessment criteria of IUCN summarized in Table 2. 
Table 2. Summary of assessment criteria of a species to be listed as critically endangered in Red List of species (IUCN 2015).

CRITICALLY ENDANGERED (CR) A taxon is Critically Endangered when the best available evidence indicates that it meets any of the following criteria (A to $\mathrm{E}$ ), and it is therefore considered to be facing an extremely high risk of extinction in the wild:

A. Reduction in population size based on any of the following:

1. An observed, estimated, inferred or suspected population size reduction of $90 \%$ over the last 10 years or three generations, whichever is the longer, where the causes of the reduction are clearly reversible AND understood AND ceased, based on (and specifying) any of the following: (a) direct observation (b) an index of abundance appropriate to the taxon (c) a decline in area of occupancy, extent of occurrence and/or quality of habitat (d) actual or potential levels of exploitation (e) the effects of introduced taxa, hybridization, pathogens, pollutants, competitors or parasites.

2. An observed, estimated, inferred or suspected population size reduction of $80 \%$ over the last 10 years or three generations, whichever is the longer, where the reduction or its causes may not have ceased OR may not be understood or may not be reversible, based on (and specifying) any of (a) to (e) under A1.

3. A population size reduction of $80 \%$, projected or suspected to be met within the next 10 years or three generations, whichever is the longer (up to a maximum of 100 years), based on (and specifying) any of (b) to (e) under A1.

4. An observed, estimated, inferred, projected or suspected population size reduction of $80 \%$ over any 10 year or three generation period, whichever is longer (up to a maximum of 100 years in the future), where the time period must include both the past and the future, and where the reduction or its causes may not have ceased OR may not be understood OR may not be reversible, based on (and specifying) any of (a) to (e) under A1.

B. Geographic range in the form of either B1 (extent of occurrence) or B2 (area of occupancy) or both:

1. Extent of occurrence ( $\left.{ }^{*} \mathrm{EOO}\right)$ estimated to be less than $100 \mathrm{~km} 2$, and estimates indicating at least two of a - c:

(a) Severely fragmented or known to exist at only a single location. (b) Continuing decline, observed, inferred or projected, in any of the following: (i) extent of occurrence (ii) area of occupancy (iii) area, extent and/or quality of habitat (iv) number of locations or subpopulations (v) number of mature individuals. (c) Extreme fluctuations in any of the following: (i) extent of occurrence (ii) area of occupancy iii) number of locations or subpopulations iv) number of mature individuals.

2. Area of occupancy ( $\left.{ }^{*} \mathrm{AOO}\right)$ estimated to be less than $10 \mathrm{~km} 2$, and estimate indicating at least two of a - c: (a) Severely fragmented or known to exist at only a single location. (b) Continuing decline, observed, inferred or projected, in any of the following: i) extent of occurrence ii) area of occupancy iii) area, extent and/or quality of habitat iv) number of locations or subpopulations v) number of mature individuals. (c) Extreme fluctuations in any of the following: (i) extent of occurrence (ii) area of occupancy (iii) number of locations or subpopulations (iv) number of mature individuals.

C. Population size estimated to number fewer than 250 mature individuals and either: 1 . An 
estimated continuing decline of at least $25 \%$ within three years or one generation, whichever is longer, (up to a maximum of 100 years in the future) OR 2. A continuing decline, observed, projected, or inferred, in numbers of mature individuals AND at least one of the following (a-b): (a) Population structure in the form of one of the following: (i) no subpopulation estimated to contain more than 50 mature individuals, OR (ii) at least $90 \%$ of mature individuals in one subpopulation. (b) Extreme fluctuations in number of mature individuals.

D. Population size estimated to number fewer than 50 mature individuals.

E. Quantitative analysis showing the probability of extinction in the wild is at least $50 \%$ within 10 years or three generations, whichever is the longer (up to a maximum of 100 years).

"EOO: The area contained within the shortest continuous imaginary boundary which can be drawn to encompass all the known, inferred or projected sites of present occurrence of a taxon, excluding cases of vagrancy.

"AOO: The area which is occupied by a taxon, excluding cases of vagrancy. The measure reflects the fact that a taxon will not usually occur throughout the area of its extent of occurrence, which may contain unsuitable or unoccupied habitats.

\section{Results and Discussion}

Habitat: Bagarius bagarius was found only from Shibpur site (S4) at Bhola Sadar Upazila in the Meghna river area out of eight sampling sites (Table 1, Fig. 1). The Meghna river is one of the largest and deepest rivers of Bangladesh. B. bagarius was found at midstream areas of the sampling locations where only medium wave actions were observed. The area was connected to local canals and experienced two times high and low tide daily. Strips of sandy land were raised in the river bed areas.

From author's Personal Communication (2017) with Department of Fisheries (DoF) officials, it is informed that B. bagarius has been noticed at Kala Badar river, Barisal in 2016(16). Recently, it was found from the Padma river at Goalondo Upazila, Rajbari district ${ }^{(17)}$.

B. bagarius lives in large rivers, particularly in deep areas(18). It prefers fast flowing waters and lives under stones and bog logs. B. bagarius has also been reported from the Padma, Jamuna, Meghna, Daleswari, Bangali, Baral, Choto Jamuna, Surma, Kushiyara, Manu Baral, Mahananda, Kangsha, Brahmaputra, Titas and Karnafully Rivers, Chalan Beel and Kaptai Reservoir(5-6).

Habitat types: B. bagarius samples were found in freshwater during this study period. Generally it lives in freshwater and the $\mathrm{pH}$ of the habitat usually ranges from 6.5 to $7.8^{(19)}$. Temperature of the water usually ranges from $18-25^{\circ} \mathrm{C}^{(20)}$.

Seasonal abundance: B. bagarius was found only at monsoon period in the month of August. A total of 8 individuals were identified at Shibpur station, Bhola district in the Meghna river. 


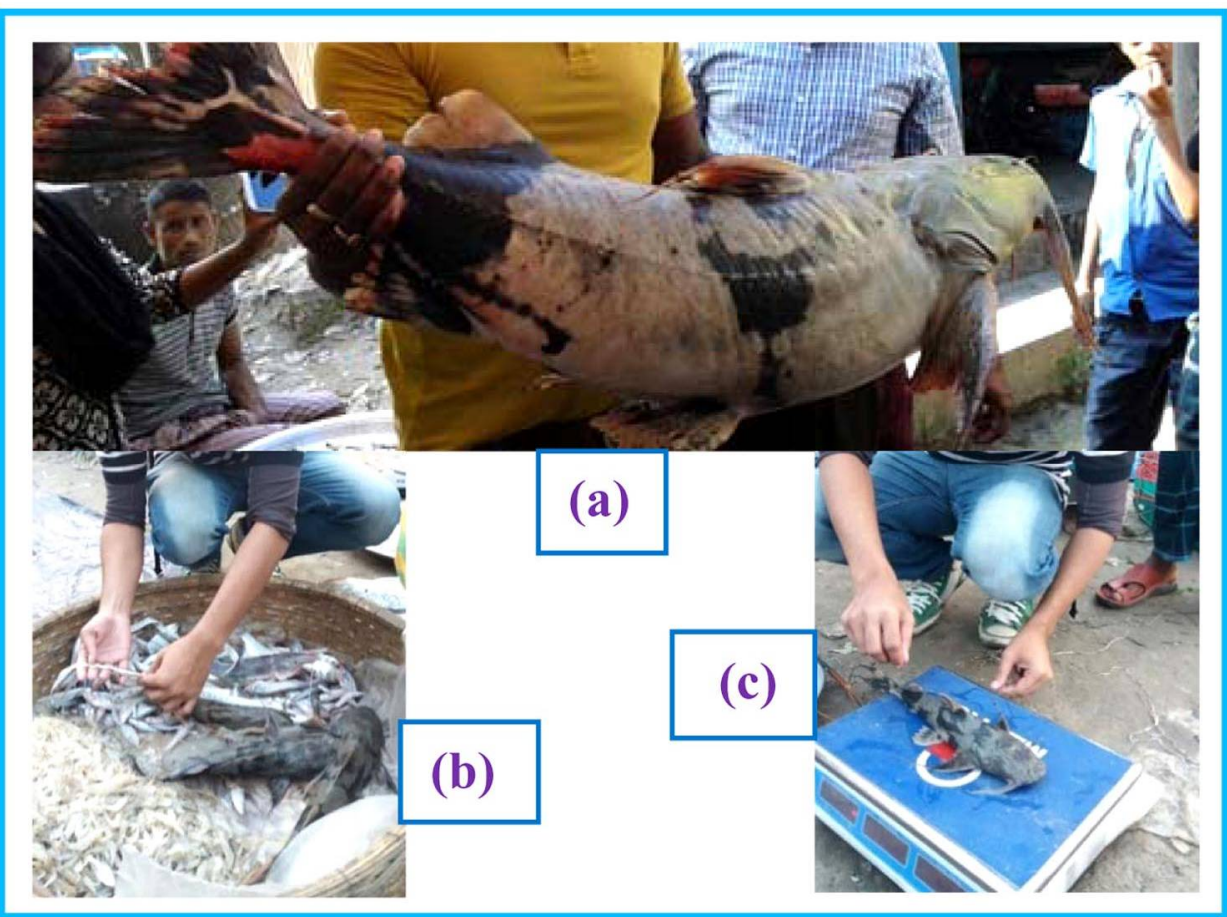

Fig. 1a-c: B. bagarius samples of different sizes. Photographs were taken by one of the authors from the Meghna River, in August 2016

Table 3. Length and weight of B. bagarius samples.

\begin{tabular}{lccccc}
\hline $\begin{array}{l}\text { Scientific } \\
\text { name }\end{array}$ & $\begin{array}{c}\text { Sample } \\
\text { No. }\end{array}$ & $\begin{array}{c}\text { Length } \\
(\mathrm{cm})\end{array}$ & Mean \pm Sd & $\begin{array}{c}\text { Weight } \\
(\mathrm{g})\end{array}$ & Mean \pm Sd \\
\hline Bagarius & 1 & 21 & \pm 1.51 & 45 & \pm 0.009 \\
bagarius & 2 & 18.1 & & 36 & \\
& 3 & 16.6 & & 24 & \\
& 4 & 18.6 & & 42 & \\
& 5 & 17.1 & & 25 & \\
& 6 & 16.1 & & 20 & \\
& 7 & 17.9 & & 32 & \\
& 8 & 18.5 & & 40 & \\
\hline
\end{tabular}

Length and weight: The length $(\mathrm{cm})$ and weight $(\mathrm{g})$ of all the collected samples are mentioned in Table 3. Among them the maximum length and weight of the collected B. bagarius specimens were recorded as $21 \mathrm{~cm}$ and $45 \mathrm{~g}$, respectively. Length of this species was previously recorded as $20-39 \mathrm{~cm}(6), 39 \mathrm{~cm}(8-9), 19 \mathrm{~cm}(21)$. It is to be noted 
that $B$. bagarius breeds before the commencement of the monsoon rains (21) which might the reason of availability of smaller size or juvenile fish.

Food and feeding habit: B. bagarius is carnivorous and predatory in nature feeding on small fishes, prawns, frogs, etc. (known from FGD at site S4: Table 1). It usually feeds on small fishes, but also preys frogs and shrimps ${ }^{(9)}$.

Threats of reduction: The population of B. bagarius has been declining since the 1990s and the cumulative population decline would be around $80 \%$ during the last 25 years ( 3 generation time)(18). A further reduction may happen because of habitat loss and its export potential(18). Although the studied species was recorded only during monsoon in the samples, FGD revealed that it was recorded frequently in fishers' catch from Meghna river, specifically using hook and line. The FGD participants also reported that the availability of larger size $(>30 \mathrm{~cm})$ B. bagarius was extremely rare in recent years $(\sim 5$ years).

Reassessment of threatened category: To conserve open water fish biodiversity, the Department of Fisheries, Government of Bangladesh in collaboration with NGOs has been implementing a set of interventions like establishment and maintenance of fish sanctuaries, fish habitat restoration, establishment of beel nurseries, stocking of fingerlings including endangered species, introduction of coordinated management approach, excavation and re-excavation of different connecting canals of rivers, dead rivers and beels, enforcement of fish conservation acts, adoption of climate-smart technologies etc. (3). While the various management and conservation interventions can improve the status of a species, increased fishing pressure, habitat loss and other causes can lead to the opposite scenario. Therefore, IUCN periodically updates its Red List of Threatened Species to address the potential positive or negative change to a degree of extinction risk of a species. The findings from the present study emphasize the necessity of revising threat categories assigned on B. bagarius over IUCN red list assessment criteria for critically endangered species.

According to IUCN (2015)(5), a taxon is Critically Endangered when the best available evidence indicates that it meets any of the criteria of $\mathrm{A}$ to $\mathrm{E}$ in the Table 2. B. bagarius was assessed as CR species in IUCN Red List of Bangladesh (2015) under CR A2cd ver 3.1 referring the declining trend in its population would be around $80 \%$ during the last 25 years (3 generation time) $)^{(18)}$. But, FGD participants of the present study remarked that although the abundance of $B$. bagarius has been reducing comparing the decade before, they have noticed the good presence of this species in their catch.

According to the criteria B1 and B2, EOO estimated to be less than $100 \mathrm{~km}^{2}$ and $\mathrm{AOO}$ estimated to be less than $10 \mathrm{~km}^{2}$, respectively for CR species. For $B$. bagarius, the recorded EOO was $82,772 \mathrm{~km}^{2}$ and AOO was $9,432 \mathrm{~km}^{2(5)}$ which are too much greater than the thresholds of $\mathrm{CR}$ category. The findings of the present study will also increase the EOO and $\mathrm{AOO}$ for B. bagarius. 
On the other hand, according to criteria $C$, the population size estimated to number fewer than 250 mature individuals and according to the criteria D, the population size estimated to number fewer than 50 mature individuals. The number of individuals reported in this study accounts for only $10 \%$ of the total catch at the study site. Therefore, total number of individuals caught by all gear types is potentially as high as 80 which was also higher than the threshold limit for criteria D. Based on the abundance in the current study and other studies in Bangladesh it can be inferred that the total abundance of mature B. bagarius is expected to be well over 250 in the natural habitats. Therefore, the current status of $B$. bagarius in natural waters in Bangladesh do not fall below the threshold limits of CR species.

Critically endangered species are of high conservation concern among the policymakers, as they are at high risk of extinction. Although B. bagarius is enlisted as critically endangered species in the IUCN Red List of Bangladesh, the findings from this study suggests that the species possess lower risk to extinction based on the criteria for $\mathrm{CR}$ in the IUCN assessment. Therefore, B. bagarius should be reclassified into a lower threatened status (but not Least Concern) than the current CR.

\section{References}

1. Nelson JS 2006. Fishes of the world. Fourth Edition. John Wiley \& Sons.

2. FAO 2007. The state of world Aquaculture and Fisheries 2006. Food and Agriculture Organization of the United Nations. Fisheries and Aquaculture Department, Rome, Italy.

3. FRSS 2017. Yearbook of Fisheries Statistics of Bangladesh. Fisheries Resources Survey System (FRSS), Department of Fisheries, Bangladesh, Vol.33. pp. 116.

4. Reid G McG, Contreras MacBeath T and K Csatadi 2013. Global challenges in freshwater fish conservation related to public aquariums and the aquarium industry. Int. Zoo. Yearbook.47(1): 6-45.

5. IUCN Bangladesh 2015. Red List of Bangladesh. Vol. 5. Freshwater Fishes. IUCN, International Union for Conservation of Nature, Bangladesh Country Office, Dhaka, Bangladesh, pp. xvi+360.

6. IUCN Bangladesh 2000. Red Book of Threatened Fishes of Bangladesh. IUCN-The World Conservation Union, pp. Xii +116 .

7. Rainboth WJ 1996. Fishes of the Cambodian Mekong. FAO species identification field guide for fishery purposes. FAO, Rome, Italy, pp. 265.

8. Rahman AKA 1989. Freshwater Fishes of Bangladesh. $1^{\text {st }}$ edition, Zoological Society of Bangladesh, Department of Zoology, University of Dhaka, Dhaka-1000, pp. 67-68.

9. Rahman AKA 2005. Freshwater Fishes of Bangladesh. 2nd edition, Zoological Society of Bangladesh, Department of Zoology, University of Dhaka, Dhaka-1000, pp. 394.

10. Galib SM, SMA Naser, ABM Mohsin, N Chaki and Fahad MFH 2013. Fish diversity of the river Choto Jamuna, Bangladesh: present status and conservation needs. Int. J. Biodivers. Conserv. 5(6): 389-395. 
11. Islam MK, KA Habib, ME Ahsan, MM Ali, and SK Basak 2015. Fish biodiversity at Sibsa River in south-western Bangladesh: status and conservation requirements. Int. J. Fish. Aquat. Stud. 4(1): 24-28.

12. Bhouiyan NA, MM Hossain and MA Baki 2016. Inventory of ichthyofaunal diversity, fishing gear and craft in Turag River, Dhaka, Bangladesh. Fish. Aquac. J. 7(2): B1-B1.

13. Habib F, S Tasnin and AS Bhuiyan NIM 2016. A checklist of fishes and fisheries of the Padda (Padma) river near Rajshahi city. Int. J. Pure App. Bio. Sci. 4(2): 53-57.

14. Pramanik MMH, MM Hasan, S Bisshas, AA Hossain and TK Biswas 2017. Fish biodiversity and their present conservation status in the Meghna River of Bangladesh. Int. J. Fish. Aquat. Stud. 5: 446-455.

15. Shafi M and MMA Quddus 2001. Fisheries of Bangladesh. Kabir Publications, Dhaka, Bangladesh, pp. 40-41.

16. Islam AM 2017. Department of Fisheries, Govt. of Bangladesh. Personal Communication. July 2017.

17. Ittefaq 2017. Bangladeshi Daily Newspaper article on 3 December 2017.

18. Mollah MAR 2015. Bagarius bagarius. In: IUCN Bangladesh. Red List of Bangladesh. Vol. 5: Freshwater Fishes. IUCN, International Union for Conservation of Nature, Bangladesh Country Office, Dhaka, Bangladesh, pp. 56.

19. Riede K 2004. Global register of migratory species - from global to regional scales. Final Report of the R\&D-Project 80805 081. Federal Agency for Nature Conservation, Bonn, Germany, pp. 329.

20. Baensch HA and R Riehl 1985. Aquarien atlas. Band 2. Mergus, Verlag für Natur-und Heimtierkunde GmbH, Melle, Germany, pp. 1216.

21. Talwar PK and AG Jhingran 1991. Inland Fishes of India and Adjacent Countries. Vol. 2. Oxford \& IBH Publishing Co. Pvt. Ltd., New Delhi-Calcutta, pp. 622-623.

(Manuscript received on 3 June, 2018; revised on 18 November, 2018) 